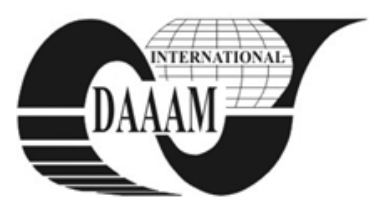

Annals of DAAAM for 2011 \& Proceedings of the 22nd International DAAAM Symposium, Volume 22, No. 1, ISSN 1726-9679 ISBN 978-3-901509-83-4, Editor B. Katalinic, Published by DAAAM International, Vienna, Austria, EU, 2011 Make Harmony between Technology and Nature, and Your Mind will Fly Free as a Bird Annals \& Proceedings of DAAAM International 2011

\title{
IMPACT OF COMBUSTION TIME OF LIGNITE IN THE MODEL OF KINETIC COMBUSTION IN THE BOILER OF "KOSOVO B"
}

\author{
MULLIQI, I[smet] S[ejdi]; TERZIQI, A[vni] K[ahriman]; BAJRAKTARI, B[ekim] V[eli] \\ \& MEHUSH RIFAT, A[liu]
}

\begin{abstract}
The process of burning of lignite in Kosovo B develops rapidly, which depends on a range of parameters of lignite and boiler. Model for impact of the duration of the burning of lignite in the kinetics of combustion process enables the definition and reflecting of thermal loads and other important indicators in boiler. The methodology of the paper is based on laboratory research of physical-chemical and granule metric analysis of lignite powder and mathematical model. The results can be used for calculations the quantities of fuel burned in the path of ideal movement in steam boiler. The purpose of drafting of this model is to create conditions for a kinetic regime more favorable of combustion
\end{abstract}

Key words: lignite, chemical composition, granule metric analysis, time

\section{INTRODUCTION}

The main parameters that affect in the burning time of lignite particles $\tau$ are the particle diameter of lignite $d$, the excess air $\lambda$, temperature in the combustion space $T$ and components of gaseous $v_{g s}$.

For impact analysis of these parameters at the time of burning particles of lignite, rely on the results of measurements for physic-chemical and granule-metric composition of lignite powder and measuring of velocity and volumetric flow of gases.

The composition of lignite with components $m C, m H, m O$, $m S, m N, m W$, and $m a$ is given in figure 1 .

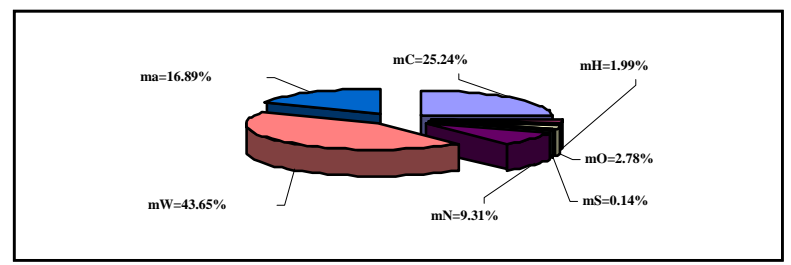

Fig. 1. Composition of lignite

Granule-metric composition of coal powder has great influence on the flows of combustion process in the hearth of the boiler, the combustion stability, the economy of combustion and in the heating of surfaces of the boiler (Djuric \& Bogner, 1980).

Results of granule-metric analysis of coal powder are reflected in figure 2 .

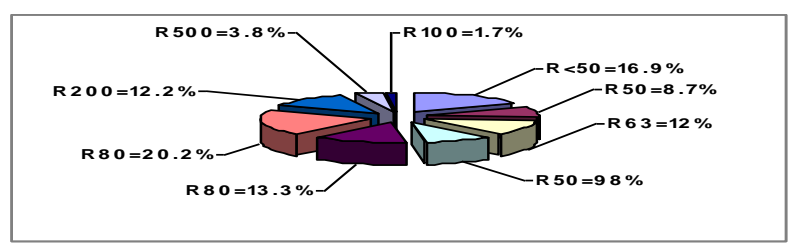

Fig. 2. Granule-metric analysis of lignite
Results of measurements carried out in line 2 of block B2 after the electro filters are given in table 1 and table 2.

\begin{tabular}{|l|l|l|l|l|l|l|}
\hline $\begin{array}{l}\text { Measuring } \\
\text { points }\end{array}$ & 1 & 2 & 3 & 4 & 5 & 6 \\
\hline 2.0 & 2.0 & 2.5 & 3.4 & $*$ & 2.3 & 2.8 \\
\hline 1.0 & 3.0 & 2.1 & 3.0 & $*$ & 1.9 & 2.0 \\
\hline
\end{tabular}

Tab. 1. Dyn. pressure measured in the block B2-line 1 in $h P a$

\begin{tabular}{|l|l|l|l|}
\hline Parameter & Method & Unit & Value \\
\hline $\begin{array}{l}\text { The surface of the } \\
\text { canal }\end{array}$ & ISO10780:1994 & $\mathrm{m}^{2}$ & 24.42 \\
\hline Dynamic pressure & ISO10780:1994 & $\mathrm{hPa}$ & 2.4 \\
\hline $\begin{array}{l}\text { Average velocity } \\
\text { of the gas }\end{array}$ & ISO10780:1994 & $\mathrm{m} / \mathrm{s}$ & 20.5 \\
\hline Gas flow & ISO10780:1994 & $\mathrm{m}^{3} / \mathrm{h}$ & 1802196 \\
\hline
\end{tabular}

Tab. 2. Physical parameters measured in block B2-line 1

Model of the submitted problem based on the results of the measurements mentioned above and the known equations of different authors.

\section{BURNING TIME OF LIGNITE AND INFLUENTIAL FACTORS}

Time of burning depending on the conversion of lignite can be determined according to equation (Knore \& Arefyev, 1966) as follows:

$$
\frac{k \tau}{\beta d_{0}}=(1-x)+\frac{1}{2} \frac{k d_{0}}{N_{u D} D}\left(1-x^{2}\right)
$$

Where are: $\beta$-mass transfer coefficient, $k$-constants of the reaction velocity, $N_{u D}$ is the number of Nusselt, $D$ the diffusion coefficient, assigned according to the following equations (McCabe, 2005):

$$
\begin{gathered}
\beta=\frac{\rho_{k o}}{0.226}\left(\frac{T}{273}\right) \\
k=k_{0} e^{-\frac{E}{R T}} \\
N_{u D}=\frac{\alpha_{D} d}{D} \\
D=D_{0}\left(\frac{T}{T_{0}}\right)^{2}
\end{gathered}
$$

Meanwhile, the minimum amount of the required air for burning of $1 \mathrm{~kg}$ of fuels is determined by the following equation (Kreuh, 1978):

$$
v_{L \min }=\{1.864 m C+5.55[m H-(m O / 8)]+0.698 m S\} / 0.21
$$


The amount of combustion products from $1 \mathrm{~kg}$ of fuel with excess air coefficient $\lambda$ determined by equation:

$$
\begin{aligned}
v_{g \lambda}= & 1.853 m C+0.7 m S+0.8 m N+0.79 v_{l \min }+ \\
& +1.24(9 m H+m V)+(\lambda-1) v_{L \min }
\end{aligned}
$$

The real density of fuel in $\mathrm{kg} / \mathrm{m}^{3}$ determined according to equation:

$$
\rho_{k}=\left\lfloor 1-\left(v_{g s} / 100\right)\right\rfloor
$$

The equation for determining the time of combustion according to Ledinegg (Gulić, 1960) is as follows.

$$
\tau=\frac{65.7 \cdot d^{2} \rho_{k}}{T\left[1+\frac{1.5(\lambda-1) v_{L \min }}{v_{g \lambda}}\right]}
$$

Where are:

$d_{0}$ - particles diameter of the fuel.

$\rho_{k o^{-}}$density of the fuel in the initial state of the combustion process, $\mathrm{kg} / \mathrm{m}^{3}$.

$v_{g s}$-gaseous components of the fuel, $\%$.

$x$ - momentary diameter of the particle $d$, referred to the initial diameter $d_{0}$.

$k_{0}$ - universal constant, $\mathrm{m} / \mathrm{s}$.

$\lambda$ - coefficient of excess air.

$E$ - activation energy.

$R$ - gas constant.

$T$ - temperature in the combustion space, $K$.

\section{CALCULATIONS AND OUTCOMES}

Model for the impact analysis of the coefficient of excess air in the time of burning requires the input data as follows: $T=1273 \mathrm{~K} ; \rho_{k o}=1200 \mathrm{~kg} / \mathrm{m}^{3} ; \lambda=1.3 ; v_{g s}=24.5 ; m C=25.24 \% ; \mathrm{mH}=$ $1.99 \% ; m O=2.78 \% ; m S=0.14 \% ; m N=9.31 \% ; m W=43.65 \%$; $m a=16.89 \%$. In the model the excess air coefficient $\lambda$ varies from 1.1 to value $1.5(\lambda=1.10 ; \lambda=1.15 ; \lambda=1.20 ; \lambda=1.25 ; \lambda=1.30$; $\lambda=1.35 ; \lambda=1.40 ; \lambda=1.45 ; \lambda=1.50)$.

The radius values of lignite particles in the calculations range from $d=0.05$ up to $d=0,0004 \mathrm{~m}$. Values of the temperature varying in the range from $T=1173 \mathrm{~K}$ up to $T=1573 \mathrm{~K}$.

Results obtained from the model are presented in Fig. 3, 4 and 5 . In figure 3 is given the functional dependence of the burning time of lignite depending on the diameter of the particle according to equation (1) and equation (9).

While in figure 4 is presented the functional dependence of the burning time of lignite from the temperature in the hearth of combustion for different diameters of lignite particles according to equation (9).

In figure 5 is given the time dependence of the burning from excess air coefficient for the different diameters of the lignite particles according to equation (9).

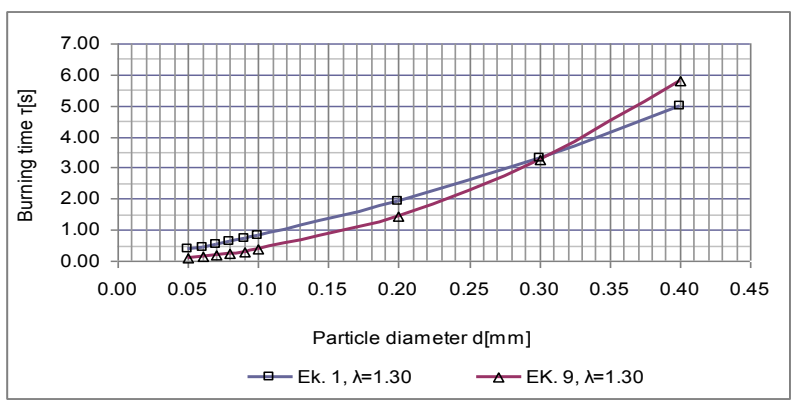

Fig. 3. $\tau=f(d)$ according to equation (1) and (2)

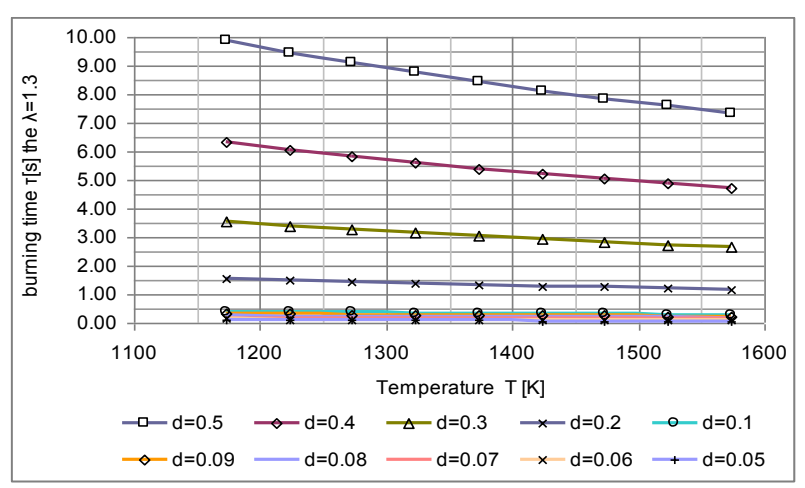

Fig. 4. $\tau=f(T)$ according to equation (9) for different diameters

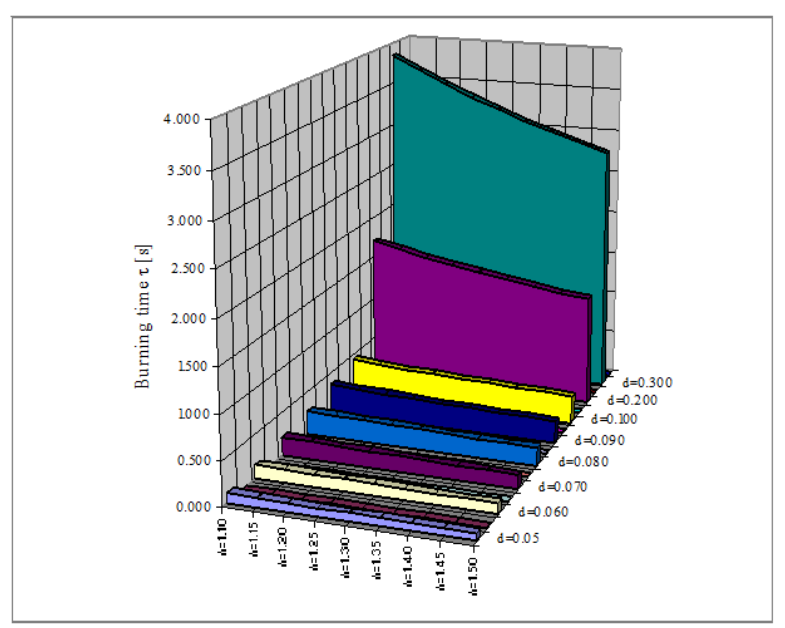

Fig. 5. $\tau=f(\lambda)$ according to equation (9) for different diameters

\section{CONCLUSION}

The burning time of the lignite particle $\tau$ with diameter $d_{0}$ according to equation (1) increases with the increase the diameter $\mathrm{d}_{0}$ and factor $\beta$, while decreases with increasing values of factors $k, N_{u D}$ and $D$ which depend on temperature.

Results obtained according to equation (9) shows that the time $\tau$ increases with the square exponent of the particles diameter of lignite $\mathrm{d}$ and is shorter for the smaller diameters $d$, for the lowest density of lignite particle $\rho_{k o}$, for the higher temperature in burning space $T$, for the largest coefficient of excess air $\lambda$ and most of the gaseous components $v_{g s}$.

Comparative results of curve according to equation (1) and (9) presented in figure 4 shows a significant relative change of burning time for the smaller diameters.

After determining the duration of the combustion process of coal powder particles can determine the mass of fuel which takes part in combustion process depending on the position of the particles, but also the position of the end of combustion process of particles depending on their diameter.

\section{REFERENCES}

Kreuh, L. (1978). Steam generators, School books, Zagreb

Djuric, V. \& Bogner, M. (1980). Steam boilers, IRO Construction book, Beograd

Gulić, G. (1960). Burning of solid liquid and gaseous fuels in steam boilers, TPK, Zagreb

Knorre, G. (1966). Theory of combustor processes, by Moscow-Leningrad

McCabe, W. (2005). Unit Operations of Chemicals Engineering, $7^{\text {th }}$ ed., ISBN 0-07-284823-5, McGraw-Hill, New York 